\title{
Thyroid Dysfunction in Patients Admitted in Cardiac Care Unit: Prevalence, Characteristic and Hospitalization Outcomes
}

This article was published in the following Dove Press journal: International Journal of General Medicine

\author{
Abdulrahman AIQahtani (D) \\ Ziyad Alakkas (D) \\ Fayez Althobaiti \\ Mohammed Alosaimi ${ }^{1}$ \\ Baraa Abuzinadah' \\ Elshazly Abdulkhalik ${ }^{2,3}$ \\ Khaled Alswat ${ }^{4}$ \\ 'Internal Medicine Department, King \\ Abdul Aziz Specialist Hospital, Taif, \\ Makkah, Saudi Arabia; ${ }^{2}$ Consultant \\ Cardiology, Cardiology Department, Al \\ Azhar University, Cairo, Egypt; \\ ${ }^{3}$ Cardiology Department, King Abdul \\ Aziz Specialist Hospital, Taif, Makkah, \\ Saudi Arabia; ${ }^{4}$ Department of Medicine, \\ College of Medicine, Taif University, Taif, \\ 21944, Saudi Arabia
}

Correspondence: Abdulrahman AlQahtani

Department of Medicine, College of Medicine, Taif University, P.O. Box 11099

Taif, 21944 , Saudi Arabia

Tel +966531901817

Email a.s.alqahtni@gmail.com
Introduction: Cardiovascular disease is one of the main causes of hospital admission and mortality, and thyroid dysfunction increases the risk of developing acute or exacerbation of chronic cardiac conditions. The aim of this study is to investigate the prevalence of thyroid hormone abnormality among patients in the cardiac care unit (CCU) patients and its relation to admission diagnosis, clinical, biochemical data, and hospital-related outcomes.

Methods: We conducted a retrospective cohort observational that included adult patients who were admitted to the CCU. We excluded those with known thyroid dysfunction and those who received amiodarone or IV contrast.

Results: A total of 374 patients with a mean age of $62.7+14.7$ years old were included. Ischemic changes were observed in $70.6 \%$ of the patients based on the admission diagnosis. In comparison to the non-ischemic group, the ischemic group was more likely to be male $(\mathrm{P}=0.010)$, to be active/former smokers $(\mathrm{P}=0.011)$, to have diabetes $(\mathrm{P}=0.009)$, to have diastolic dysfunction $(\mathrm{P}=<0.001)$, to have undergone thrombolysis $(\mathrm{P}=<0.001)$, and to have been referred to a tertiary center $(\mathrm{P}=<0.001)$. Euthyroidism was observed in $57.8 \%$ of the patients based on the thyroid function test at admission. Compared to patients with thyroid dysfunction, those with Euthyroidism were more likely to be active/former smokers $(\mathrm{P}=0.002)$, to have lower heart rates $(\mathrm{P}=0.018)$, to not have chronic kidney disease $(\mathrm{P}=0.016)$, to not have heart failure $(\mathrm{P}=0.006)$, to have lower thyroid-stimulating hormone (TSH) levels $(\mathrm{P}=<0.001)$, and to have lower tricuspid regurgitation $(\mathrm{P}=0.042)$.

Conclusion: Thyroid dysfunction is common among patients admitted to the CCU. Nonsignificant positive correlations between TSH and hospitalization length, tertiary center referral, 30-day readmission, and in-hospital mortality when adjusting for potential confounders.

Keywords: thyroid disease, sick euthyroid, acute coronary syndrome, heart failure, ischemic heart disease, nonthyroidal illness syndrome, NTIS

\section{Introduction}

Cardiovascular disease poses one of the heaviest burdens on any health-care system. It is responsible for more than 17 million deaths worldwide and is one of the main causes of hospital admission. The prevalence of ischemic cardiac disease and its complications is the highest. Thus, the spotlight has been shined on primary and secondary prevention and identifying conditions that increase the risk of cardiac events through both biochemical and clinical data. ${ }^{1}$

Thyroid hormone has a major effect on the cardiovascular system. ${ }^{2-4}$ Changes in thyroid hormone levels (either up or down) produce effects on heart contractility, 
oxygen consumption, and systemic vascular resistance. ${ }^{5}$ The diagnosis and management of thyroid disorders are crucial as most of these changes are reversible. Thyroid disorders are common, affecting around $9-15 \%$ of the adult population and being more common in females, although the rate becomes more equal between men and women at advanced ages. ${ }^{6}$

Patients with hyperthyroidism usually present with symptoms and signs that are more related to the cardiovascular system. ${ }^{7}$ A state of hyperthyroidism affects the hemodynamics of the heart and increases the heart rate, systolic blood pressure, cardiac output, contractility, and left ventricular ejection fraction (LVEF), while it decreases peripheral vascular resistance. In severe cases of hyperthyroidism, these changes may eventually lead to high-output heart failure. In fact, some use the term "thyrotoxic cardiomyopathy" to describe the damage that may happen because of a severe chronic hyperthyroid state. ${ }^{3}$

An increased incidence of atrial fibrillation with hyperthyroidism has been well identified. The range of incidence is $2-20 \%,{ }^{8}$ with $13.8 \%$ occurring in cases of overt hyperthyroidism, as opposed to $2.3 \%$ in the general population, ${ }^{9}$ especially in the elderly and those with cardiac disease. ${ }^{10,11}$ Hashimoto and Graves diseases are both noted to be more associated with mitral valve prolapse, which might be followed left atrium enlargement and atrial fibrillation. ${ }^{12}$ Subclinical hyperthyroidism may increase risk for mortality, coronary artery disease, and atrial fibrillation. ${ }^{13}$ Low thyroid-stimulating hormone (TSH) was linked with more risk for atrial fibrillation, ${ }^{14}$ and mortality from cardiovascular diseases. ${ }^{15}$

In contrast, hypothyroidism manifests with decreased heart rate, cardiac contractility, and cardiac output, along with a mild increase in diastolic blood pressure due to the effect on the renin-angiotensin-aldosterone system. ${ }^{6}$ Although these changes rarely cause heart failure by themselves, they may lead to worsening clinical conditions in patients with heart failure, as well as worsening hospital outcomes. ${ }^{16}$ Furthermore, hypothyroidism has been identified to affect lipid metabolism, and multiple studies have found that it is associated with higher cholesterol and lowdensity lipoprotein (LDL) levels. ${ }^{17}$ The prevalence of subclinical hypothyroidism is $7-10 \%$ among older women, and it has an effect on lipid metabolism ${ }^{17,18}$ with increased lipid and cholesterol levels, which appear to be parallel with serum $\mathrm{TSH}^{7,19}$ accelerated atherosclerosis, and coronary artery disease. ${ }^{20}$
It has been found that $23.3 \%$ of the patients with acute myocardial infarction have Nonthyroidal Illness Syndrome (NTIS), which improves the predictive value of in-hospital cardiovascular deaths in such patients. ${ }^{21}$ It has also been linked in past and recent data with increased risk of allcause mortality and major adverse cardiac events (MACE). ${ }^{22}$ Cardiovascular diseases are some of the major causes of hospital admission and the leading cause of death worldwide. Furthermore, thyroid dysfunction is a risk factor for cardiac disease, as well as mortality among patients with cardiac disease. ${ }^{1,23}$ Thus, the aim of this study is to investigate the prevalence of thyroid hormone abnormality in cardiac care unit (CCU) patients and its relation to admission diagnosis, clinical, biochemical data, and hospital-related outcomes.

\section{Patients and Methods}

A retrospective cohort observational study was conducted in the Cardiology Department at King Abdul Aziz Specialist Hospital in Taif City, Saudi Arabia. A total of 411 patients were considered for enrollment. The patients were selected from those who were admitted to the CCU due to acute cardiovascular events or exacerbation of chronic cardiac condition between December 2015 and December 2018.

The inclusion criteria were age older than 18 years, both sexes, and no known thyroid disease. We excluded 37 patients because they either had a history of thyroid disease or received amiodarone or IV contrast before blood extraction. After the exclusion, 374 patients were included. The data collected included diagnosis at admission, past medical history of either underlying cardiac disease or other conditions that are considered as a risk factor for cardiac disease, special habits, length of hospitalization, electrocardiograms, echocardiographic evaluations, clinical and biochemical data, and hospitalization-related outcomes.

Laboratory investigations included triglyceride (TGL), high-density lipoprotein (HDL), LDL, total cholesterol, and thyroid function tests (free thyroxine (FT4), free triiodothyronine (FT3), and TSH). The levels were measured from venous blood samples extracted at admission. The results were interpreted by a board-certified endocrinologist, and patients were categorized according to their thyroid state (Table 1) and as it listed FT4 had no significance to reaching the diagnosis of NTIS as it can be falsely high, normal, or low in ill patients as an effect of received treatment or due to the illness itself. ${ }^{24}$ Results that did 
Table I Interpretation of Thyroid Function Test

\begin{tabular}{|c|c|c|c|}
\hline Thyroid Profile Interpretation & TSH & Free T4 & Free T3 \\
\hline T3 toxicosis & Low & Normal & High \\
\hline \multirow[t]{2}{*}{ Non-thyroidal illness syndrome } & Normal & $\begin{array}{l}\text { High } \\
\text { Normal } \\
\text { Low }\end{array}$ & \multirow[t]{2}{*}{ Low } \\
\hline & Low & $\begin{array}{l}\text { Normal } \\
\text { High }\end{array}$ & \\
\hline Clinical hyperthyroidism & $\begin{array}{l}\text { Low } \\
\text { High* }\end{array}$ & High & High \\
\hline Clinical hypothyroidism & $\begin{array}{l}\text { High } \\
\text { Low* }\end{array}$ & Low & Normal-Low \\
\hline Subclinical hyperthyroidism & Low & Normal & Normal \\
\hline Subclinical hypothyroidism & High & Normal & Normal \\
\hline
\end{tabular}

Note: *In case of central axis dysfunction.

Abbreviations: T3, triiodothyronine; T4, thyroxine; TSH, thyroid-stimulating hormone.

not fit any of the mentioned conditions were classified as uninterpretable.

Echocardiographic evaluation was conducted by a certified cardiologist (Philips CX50 Echocardiography). Information on left ventricular ejection fraction (LVEF), diastolic dysfunction, left ventricular hypertrophy (LVH), and valvular pathology were collected for all patients. Furthermore, we documented the presence of left or right bundle branch block through 12-lead electrocardiograms.

According to the diagnosis upon admission, patients were categorized into an ischemic group and nonischemic group. We compared these groups' baseline characteristics, thyroid state, underlying chronic diseases (both cardiac and non-cardiac), biochemical data, echocardiographic findings, and hospitalization-related outcomes. The study proposal was submitted to and approved by the Institutional Review Board (IRB) at Taif Health Affairs and the Medical Research Unit at King Abdul Aziz Specialist Hospital.

All qualitative and quantitative data were collected from patients' medical records. The data were entered and coded through Microsoft Excel (Microsoft, Redmond, WA, USA) and analyzed using SPSS version 26 (SPSS Inc., Chicago, IL, USA). The clinical characteristics were compared for patients with and without thyroid dysfunction, and we defined statistical significance as $\mathrm{p}<$ 0.05. Chi-squared tests were performed for categorical variables, and unpaired t-tests were used for continuous variables.

\section{Results}

The 374 patients had a mean age of $62.7+14.7$ years, were mostly Saudi males, and had a mean hospital stay of $4.0+4.4$ days (Table 2). One-third of the sample was active/former smokers, and around 5\% of them had right or left bundle branch block on electrocardiograms. The most common admission diagnosis was acute coronary syndrome, followed by heart failure. The least common diagnosis was valvular, congenital, and acute aortic syndrome. The most common thyroid diagnosis based on the thyroid function test at admission was euthyroidism, followed by NTIS, and the least common ones were T3 toxicosis and subclinical hyperthyroidism.

The most common chronic diseases were hypertension, followed by diabetes mellitus (DM), and the least common were peripheral artery disease and non-ischemic cardiomyopathy. The mean results of the thyroid function test and lipid profile were in the normal/controlled range. Regarding the echocardiographic findings, one-third of the patients had LVH, while more than half of them had diastolic dysfunction and mitral regurgitation. More than half of the patients were referred to a tertiary center for intervention, and the in-hospital mortality rate was 5.9\%.

Ischemic changes were observed in $70.6 \%$ of the patients based on the admission diagnosis (Table 3). Compared to the non-ischemic group, the ischemic group was more likely to be male $(\mathrm{P}=0.010)$, to have a shorter hospital stay $(\mathrm{P}=0.012)$, to be active/former smokers $(\mathrm{P}=0.011)$, to have higher oxygen saturation $(\mathrm{P}=0.001)$, 
Table 2 Baseline Characteristics of the Whole Cohort

\begin{tabular}{|c|c|}
\hline \multicolumn{2}{|l|}{ Baseline Characteristics $(\mathrm{N}=374)$} \\
\hline Mean age (years) & $62.7 \pm 14.7$ \\
\hline Female (\%) & 31.3 \\
\hline Saudi (\%) & 88.5 \\
\hline Length of hospitalization (days) & $4.0 \pm 4.4$ \\
\hline Active/former smoking (\%) & 31.3 \\
\hline Mean systolic blood pressure $(\mathrm{mmHg})$ & $|4| .6 \pm 3 \mid .2$ \\
\hline Mean diastolic blood pressure $(\mathrm{mmHg})$ & $77.8 \pm 17.1$ \\
\hline Heart rate (beats per minute) & $86.6 \pm 24.5$ \\
\hline Oxygen saturation (\%) & $92.9 \pm 7.2$ \\
\hline Electrocardiogram with left bundle branch block (\%) & 5.1 \\
\hline Electrocardiogram with Right bundle branch block (\%) & 5.3 \\
\hline \multicolumn{2}{|l|}{ Admission diagnosis } \\
\hline Acute coronary syndrome (\%) & 69.3 \\
\hline Chronic coronary syndrome (\%) & 1.3 \\
\hline Heart failure (\%) & 12.0 \\
\hline Arrhythmia (\%) & 8.0 \\
\hline Myocardial disease (\%) & 0.8 \\
\hline Pericardial disease (\%) & 0.5 \\
\hline Valvular heart disease (\%) & 0.3 \\
\hline Adult congenital heart disease (\%) & 0.3 \\
\hline Acute aortic syndrome (\%) & 0.3 \\
\hline Cardiac arrest outside the hospital (\%) & 0.5 \\
\hline Other diagnosis (\%) & 6.7 \\
\hline \multicolumn{2}{|l|}{$\begin{array}{l}\text { Thyroid diagnosis based on admission thyroid } \\
\text { function test }\end{array}$} \\
\hline Primary hyperthyroidism (\%) & 1.9 \\
\hline Primary hypothyroidism (\%) & 4.3 \\
\hline Subclinical hyperthyroidism (\%) & I.I \\
\hline Subclinical hypothyroidism (\%) & 10.2 \\
\hline NTIS (\%) & 15.0 \\
\hline Euthyroid (\%) & 57.8 \\
\hline T3 thyrotoxicosis (\%) & 0.3 \\
\hline Uninterpretable (\%) & 9.6 \\
\hline \multicolumn{2}{|l|}{ Chronic diseases } \\
\hline Diabetes mellitus (\%) & 62.8 \\
\hline Hypertension (\%) & 64.7 \\
\hline Stroke (\%) & 5.1 \\
\hline Peripheral vascular disease (\%) & 1.6 \\
\hline Chronic kidney disease (\%) & 11.8 \\
\hline End-stage renal disease (\%) & 2.1 \\
\hline Ischemic heart disease (\%) & 36.9 \\
\hline Heart failure (\%) & 11.8 \\
\hline Atrial fibrillation (\%) & 5.3 \\
\hline Ischemic cardiomyopathy (\%) & 11.0 \\
\hline Non-ischemic cardiomyopathy (\%) & 1.9 \\
\hline \multicolumn{2}{|l|}{ Laboratory data } \\
\hline TSH (ulU/mL) & $4.4 \pm 14.9$ \\
\hline Free T4 (pmol/L) & $14.7 \pm 3.5$ \\
\hline Free T3 (pmol/L) & $4.2 \pm 1.4$ \\
\hline
\end{tabular}

(Continued)
Table 2 (Continued).

\begin{tabular}{|l|l|}
\hline \multicolumn{2}{|l|}{ Baseline Characteristics (N= 374) } \\
\hline Total cholesterol (mg/dL) & $166.7 \pm 50.5$ \\
LDL (mg/dL) & $103.8 \pm 44.1$ \\
HDL (mg/dL) & $38.2 \pm 18.1$ \\
Triglyceride (mg/dL) & $148.4 \pm 92.9$ \\
\hline Echocardiographic findings & \\
Left ventricular hypertrophy (\%) & 32.4 \\
Diastolic dysfunction (\%) & 53.2 \\
Ejection fraction (\%) & $49.2 \pm 14.8$ \\
Mitral regurgitation (\%) & 50.8 \\
Mitral stenosis (\%) & 2.7 \\
Tricuspid regurgitation (\%) & 30.2 \\
Tricuspid stenosis (\%) & 2.7 \\
Aortic regurgitation (\%) & 12.6 \\
Aortic stenosis (\%) & 4.5 \\
Pulmonary regurgitation (\%) & 3.2 \\
Pulmonary stenosis (\%) & 2.4 \\
\hline Hospitalization-related outcomes & \\
Thrombolytic therapy (\%) & 14.4 \\
Referred to tertiary hospital (\%) & 53.7 \\
Discharge against medical advice (\%) & 9.4 \\
30 days readmission (\%) & 1.9 \\
In-hospital mortality (\%) & 5.9 \\
\hline
\end{tabular}

to have DM $(\mathrm{P}=0.009)$, to have higher total cholesterol levels $(\mathrm{P}=<0.001)$, to have higher LDL levels $(\mathrm{P}=0.001)$, to have higher TGL levels ( $\mathrm{P}=0.007)$, to have diastolic dysfunction $(\mathrm{P}=<0.001)$, to have undergone thrombolysis $(\mathrm{P}=<0.001)$, and to be referred to a tertiary center $(\mathrm{P}=<0.001)$. The ischemic group was less likely to have chronic kidney disease $(\mathrm{P}=<0.001)$, heart failure $(\mathrm{P}=<0.001)$, atrial fibrillation $(\mathrm{P}=<0.001)$, cardiomyopathy $(\mathrm{P}=<0.001)$, mitral regurgitation $(\mathrm{P}=0.030)$, tricuspid regurgitation $(\mathrm{P}=0.006)$, and aortic stenosis $(\mathrm{P}=0.029)$ when compared to the non-ischemic group.

Euthyroidism was observed in $57.8 \%$ of the patients based on the thyroid function test at admission (Table 4). Compared to those with thyroid dysfunction, those with euthyroidism were more likely to be active/former smokers $(\mathrm{P}=0.002)$, to have lower heart rates $(\mathrm{P}=0.018)$, to not have chronic kidney disease $(\mathrm{P}=0.016)$, to not have heart failure ( $\mathrm{P}=0.006)$, to have lower TSH levels $(\mathrm{P}=<0.001)$, to have lower tricuspid regurgitation $(\mathrm{P}=0.042)$, and to have lower aortic regurgitation $(\mathrm{P}=0.007)$. The highest TSH level was observed in those with heart failure and acute aortic syndrome, while the lowest was observed in those with pericardial disease (Figure 1). 
Table 3 Baseline Characteristics Based on the Admission Diagnosis Category

\begin{tabular}{|c|c|c|c|}
\hline & Ischemic & Non-Ischemic & $P$ value \\
\hline Patients (\%) & 70.6 & 29.4 & $\mathrm{n} / \mathrm{a}$ \\
\hline Mean age (years) & $62.6 \pm 13.1$ & $62.9 \pm 18.2$ & 0.874 \\
\hline Female (\%) & 27.3 & 40.9 & 0.010 \\
\hline Saudi (\%) & 88.3 & 89.1 & 0.818 \\
\hline Length of hospitalization (days) & $3.5 \pm 2.8$ & $5.2 \pm 6.7$ & 0.012 \\
\hline Active/former smoking (\%) & 35.2 & 21.8 & 0.011 \\
\hline Mean systolic blood pressure $(\mathrm{mmHg})$ & $140.9 \pm 30.7$ & $143.2 \pm 32.5$ & 0.518 \\
\hline Mean diastolic blood pressure $(\mathrm{mmHg})$ & $78.5 \pm 17.1$ & $76.2 \pm 17.0$ & 0.218 \\
\hline Heart rate (beats per minute) & $84.9 \pm 19.2$ & $90.7 \pm 33.8$ & 0.098 \\
\hline Oxygen saturation (\%) & $93.9 \pm 5.9$ & $90.6 \pm 9.5$ & 0.001 \\
\hline Electrocardiogram with left bundle branch block (\%) & 3.8 & 8.2 & 0.078 \\
\hline Electrocardiogram with Right bundle branch block (\%) & 4.2 & 8.2 & 0.116 \\
\hline \multicolumn{4}{|c|}{ Thyroid diagnosis based on admission thyroid function test } \\
\hline Primary hyperthyroidism (\%) & 1.9 & 1.8 & 0.147 \\
\hline Primary hypothyroidism (\%) & 3.4 & 6.4 & \\
\hline Subclinical hyperthyroidism (\%) & 1.1 & 0.9 & \\
\hline Subclinical hypothyroidism (\%) & 7.6 & 16.4 & \\
\hline NTIS (\%) & 14.4 & 16.4 & \\
\hline Euthyroid (\%) & 60.2 & 51.8 & \\
\hline T3 thyrotoxicosis (\%) & 0.4 & 0.0 & \\
\hline Uninterpretable (\%) & 7.8 & 6.4 & \\
\hline \multicolumn{4}{|l|}{ Chronic diseases } \\
\hline Diabetes mellitus (\%) & 67.0 & 52.7 & 0.009 \\
\hline Hypertension (\%) & 63.6 & 67.3 & 0.503 \\
\hline Stroke (\%) & 5.3 & 4.5 & 0.761 \\
\hline Peripheral vascular disease (\%) & 1.1 & 2.7 & 0.265 \\
\hline Chronic kidney disease (\%) & 6.1 & 25.5 & $<0.001$ \\
\hline End-stage renal disease (\%) & 2.3 & 1.8 & 0.782 \\
\hline Ischemic heart disease (\%) & 38.6 & 32.7 & 0.281 \\
\hline Heart failure (\%) & 3.0 & 32.7 & $<0.001$ \\
\hline Atrial fibrillation (\%) & 1.9 & 13.6 & $<0.001$ \\
\hline Ischemic cardiomyopathy (\%) & 8.3 & 17.3 & $<0.001$ \\
\hline Non-ischemic cardiomyopathy (\%) & 0.4 & 5.5 & \\
\hline \multicolumn{4}{|l|}{ Laboratory data } \\
\hline TSH (ulU/mL) & $4.4 \pm 17$ & $4.2 \pm 6.4$ & 0.900 \\
\hline Free T4 (pmol/L) & $14.6 \pm 3.7$ & $14.9 \pm 3.2$ & 0.387 \\
\hline Free T3 (pmol/L) & $4.2 \pm 1.3$ & $4.1 \pm 1.6$ & 0.268 \\
\hline Total cholesterol (mg/dL) & $174.4 \pm 48.3$ & $|48.3 \pm 5| . \mid$ & $<0.001$ \\
\hline $\mathrm{LDL}(\mathrm{mg} / \mathrm{dL})$ & $109.3 \pm 43.8$ & $90.8 \pm 42.2$ & 0.001 \\
\hline $\mathrm{HDL}(\mathrm{mg} / \mathrm{dL})$ & $38.4 \pm 14.7$ & $37.6 \pm 24.5$ & 0.737 \\
\hline Triglyceride (mg/dL) & $158.2 \pm 100.0$ & $|25| \pm 69.0$. & 0.007 \\
\hline \multicolumn{4}{|l|}{ Echocardiographic findings } \\
\hline Left ventricular hypertrophy (\%) & 33 & 30.9 & 0.590 \\
\hline Diastolic dysfunction (\%) & 55.3 & 48.2 & $<0.001$ \\
\hline Ejection fraction (\%) & $49.5 \pm 14.0$ & $48.5 \pm 16.5$ & 0.561 \\
\hline Mitral regurgitation (\%) & 48.1 & 57.3 & 0.030 \\
\hline Mitral stenosis (\%) & 3.0 & 1.8 & 0.722 \\
\hline Tricuspid regurgitation (\%) & 26.1 & 40.0 & 0.006 \\
\hline Tricuspid stenosis (\%) & 2.7 & 2.7 & 0.967 \\
\hline
\end{tabular}

(Continued) 
Table 3 (Continued).

\begin{tabular}{|l|l|l|l|}
\hline & Ischemic & Non-Ischemic & P value \\
\hline Aortic regurgitation (\%) & 12.5 & 12.6 & 0.865 \\
Aortic stenosis (\%) & 3.0 & 8.2 & 0.029 \\
Pulmonary regurgitation (\%) & 3.0 & 3.2 & 0.762 \\
Pulmonary stenosis (\%) & 2.3 & 2.7 & 0.794 \\
\hline Hospitalization-related outcomes & & & \\
Thrombolytic therapy (\%) & 20.5 & 0.0 & $<0.001$ \\
Referred to tertiary hospital (\%) & 65.9 & 24.5 & $<0.001$ \\
Discharge against medical advice (\%) & 9.8 & 8.2 & 0.614 \\
30 days readmission (\%) & 2.7 & 0.0 & 0.085 \\
In-hospital mortality (\%) & 5.3 & 7.3 & 0.461 \\
\hline
\end{tabular}

Table 4 Baseline Characteristics Based on the Admission Thyroid Function Test

\begin{tabular}{|c|c|c|c|}
\hline & Euthyroid & Thyroid Dysfunction & $P$ value \\
\hline Patients (\%) & 57.8 & 42.2 & $\mathrm{n} / \mathrm{a}$ \\
\hline Mean age (years) & $61.5 \pm 14.3$ & $64.3 \pm 15.1$ & 0.069 \\
\hline Female (\%) & 27.8 & 36.1 & 0.087 \\
\hline Saudi (\%) & 87.0 & 99.5 & 0.299 \\
\hline Length of hospitalization (days) & $3.6 \pm 4.5$ & $4.5 \pm 4.3$ & 0.068 \\
\hline Active/former smoking (\%) & 37.5 & 22.8 & 0.002 \\
\hline Mean systolic blood pressure $(\mathrm{mmHg})$ & $|4| .3 \pm 30.6$ & $142.0 \pm 32.2$ & 0.826 \\
\hline Mean diastolic blood pressure $(\mathrm{mmHg})$ & $78.5 \pm 17.9$ & $76.9 \pm 15.9$ & 0.362 \\
\hline Heart rate (beats per minute) & $84.1 \pm 22.9$ & $90.1 \pm 26.2$ & 0.018 \\
\hline Oxygen saturation (\%) & $93.2 \pm 7.8$ & $92.6 \pm 6.5$ & 0.431 \\
\hline Electrocardiogram with left bundle branch block (\%) & 3.7 & 7.0 & 0.156 \\
\hline Electrocardiogram with Right bundle branch block (\%) & 6.0 & 4.4 & 0.500 \\
\hline \multicolumn{4}{|l|}{ Admission diagnosis } \\
\hline Acute coronary syndrome (\%) & 72.7 & 64.6 & 0.256 \\
\hline Chronic coronary syndrome (\%) & 0.9 & 1.9 & \\
\hline Heart failure (\%) & 8.8 & 16.5 & \\
\hline Arrhythmia (\%) & 8.8 & 7.0 & \\
\hline Myocardial disease (\%) & 1.4 & 0.0 & \\
\hline Pericardial disease (\%) & 0.5 & 0.6 & \\
\hline Valvular heart disease $(\%)$ & 0.5 & 0.0 & \\
\hline Adult congenital heart disease (\%) & 0.5 & 0.0 & \\
\hline Acute aortic syndrome (\%) & 0.0 & 0.6 & \\
\hline Cardiac arrest outside the hospital (\%) & 0.5 & 0.6 & \\
\hline Other diagnosis (\%) & 5.6 & 8.2 & \\
\hline \multicolumn{4}{|l|}{ Chronic disease } \\
\hline Diabetes mellitus (\%) & 63.9 & 61.4 & 0.622 \\
\hline Hypertension (\%) & 64.4 & 65.2 & 0.867 \\
\hline Stroke (\%) & 4.2 & 6.3 & 0.347 \\
\hline Peripheral vascular disease (\%) & 1.4 & 1.9 & 0.698 \\
\hline Chronic kidney disease (\%) & 8.3 & 16.5 & 0.016 \\
\hline End-stage renal disease (\%) & 1.4 & 3.2 & $0.24 I$ \\
\hline Ischemic heart disease (\%) & 35.2 & 39.2 & 0.422 \\
\hline Heart failure (\%) & 7.9 & 17.1 & 0.006 \\
\hline Atrial fibrillation (\%) & 5.1 & 5.7 & 0.798 \\
\hline
\end{tabular}

(Continued) 
Table 4 (Continued).

\begin{tabular}{|c|c|c|c|}
\hline & Euthyroid & Thyroid Dysfunction & $P$ value \\
\hline Ischemic cardiomyopathy (\%) & 9.3 & 13.3 & 0.321 \\
\hline \multicolumn{4}{|l|}{ Laboratory data } \\
\hline Free T3 (pmol/L) & $4.3 \pm 0.9$ & $4.1 \pm 1.8$ & 0.275 \\
\hline Total cholesterol (mg/dL) & $17 \mid .6 \pm 49.2$ & $|60.0 \pm 5| .7$ & 0.057 \\
\hline LDL (mg/dL) & $106.4 \pm 42.3$ & $100.4 \pm 46.4$ & 0.262 \\
\hline $\mathrm{HDL}(\mathrm{mg} / \mathrm{dL})$ & $37.2 \pm 10.4$ & $39.5 \pm 25.0$ & 0.282 \\
\hline \multicolumn{4}{|l|}{ Echocardiographic findings } \\
\hline Left ventricular hypertrophy (\%) & 33.8 & 30.4 & 0.735 \\
\hline Diastolic dysfunction (\%) & 51.9 & 55.1 & 0.316 \\
\hline Ejection fraction (\%) & $50.4 \pm 14.4$ & $47.5 \pm 15.1$ & 0.063 \\
\hline Mitral regurgitation (\%) & 47.7 & 55.1 & 0.054 \\
\hline Mitral stenosis (\%) & 2.3 & 3.2 & 0.499 \\
\hline Tricuspid regurgitation (\%) & 28.7 & 32.3 & 0.042 \\
\hline Tricuspid stenosis (\%) & 2.3 & 3.2 & 0.615 \\
\hline Aortic regurgitation (\%) & 7.9 & 19.0 & 0.007 \\
\hline Aortic stenosis (\%) & 4.6 & 4.4 & 0.927 \\
\hline Discharge against medical advice (\%) & 9.3 & 9.5 & 0.939 \\
\hline 30 days readmission $(\%)$ & 1.9 & 1.9 & 0.974 \\
\hline In-hospital mortality (\%) & 3.7 & 8.9 & 0.036 \\
\hline
\end{tabular}

Partial correlation analyses were done with adjustments for gender, age, total cholesterol, HDL, TGL, LDL, systolic and diastolic blood pressure, heart rate, oxygen saturation, DM, hypertension, cerebrovascular accident, peripheral vascular disease, chronic kidney disease, and end-stage renal disease and smoking history. The results showed non-significant positive correlations between TSH and each of the following: 30-day readmission $(\mathrm{r}=0.15$, $\mathrm{P}=0.815)$, in-hospital mortality $(\mathrm{r}=0.026, \mathrm{P}=0.679)$, referral to a tertiary center $(r=0.058, P=0.349)$, and length of hospital stay $(\mathrm{r}=0.034, \mathrm{P}=0.590)$.

\section{Discussion}

This study showed that most patients were male with a mean age of $62.7+14.7$ years. A recent study showed similar sex and mean-age distributions to those observed in our study. ${ }^{25}$ Around $5 \%$ of the patients in our study had right and left bundle branch blocks, which is like a previous study. ${ }^{26}$ The prevalence of the left bundle branch block was higher in the previous study, and this difference is likely due to the lower percentage of the heart failure patients in our study. ${ }^{27}$

The most common diagnosis on admission was acute coronary syndrome, which had a prevalence of $69.3 \%$. This is consistent with a recently published study. ${ }^{28}$ NTIS was only present in $15 \%$ of the patients which is similar to previous studies, ${ }^{29,30}$ while euthyroidism was prevalent in $57.8 \%$. A recent study on critically ill patients showed that $84 \%$ of the patients having altered thyroid function. ${ }^{31}$ Most patients had DM and hypertension, and half of the sample had diastolic dysfunction. A recent systemic review showed that $48 \%$ of the hospitalized patients had diastolic dysfunction, which is consistent with our findings. ${ }^{32}$ The in-hospital mortality rate in our study was $5.9 \%$, which is slightly higher than reported in a previous study from the United States, which showed an average annual rate of 3.4\%. ${ }^{33}$ This difference is likely related to the study design and duration, along 


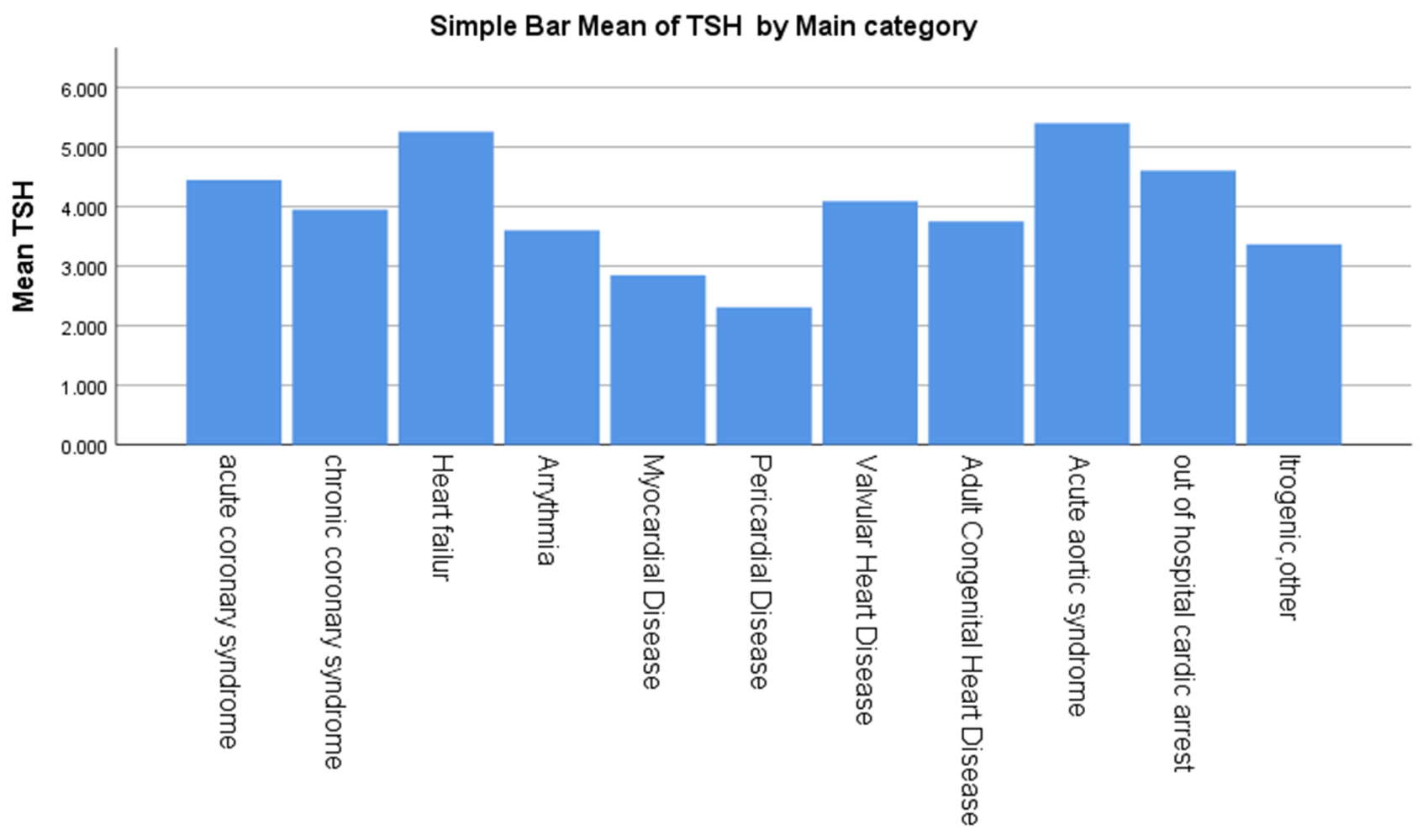

Figure I The mean TSH according to the admission diagnosis.

with the lack of facilities like cardiac catheterization units at our hospital.

In our study, $70 \%$ of the patients had ischemic changes, which were more common among males. This concurs with a previous study with a similar age distribution. ${ }^{34}$ Our study showed that $53.2 \%$ of the patients had diastolic dysfunction, which is also like other studies. ${ }^{35,36}$ Valvular disease was more prevalent in the non-ischemic group, as reported previously. ${ }^{37}$ This is likely explained by those with valvular disease presenting with heart failure rather than ischemic changes.

Our study showed that TSH is positively associated with 30-day hospital readmission, in-hospital mortality, referral to a tertiary center, and length of hospital stay. A recent study showed that TSH more than 4 is correlated with worse hospital outcomes. ${ }^{38}$ Another recent study showed that women with high TSH were at significantly higher risk of increased mortality from coronary artery disease. ${ }^{39}$ Most of our patients were male, and this more likely why our result was non-significant.

\section{Conclusion}

Thyroid dysfunction is common among patients admitted to the CCU, among which NTIS was been the most common diagnosis. Non-significant positive correlations between TSH and hospitalization length, tertiary center referral, 30-day readmission, and in-hospital mortality when adjusting for potential confounders.

\section{Abbreviations}

CCU, cardiac care unit; NTIS, non-thyroidal illness syndrome; TSH, thyroid-stimulating hormone; FT4, Free thyroxine; FT3, Free triiodothyronine; LVEF, left ventricular ejection fraction; LVH, left ventricular hypertrophy; LDL, Low-density lipoprotein; HDL, high-density lipoprotein; TGL, triglyceride; DM, diabetes mellitus; MACE, major adverse cardiac events; IRB, Institutional Review Board.

\section{Ethics Approval and Consent to Participate}

There are no apparent issues that interfere with the routine care of patients while conducting the study and as this study did not involve any treatment or intervention, due to the retrospective nature of it, so no consent was needed as it was approved by the Institutional Review Board (IRB) at Taif Health Affairs and the Medical Research Unit at King Abdul Aziz Specialist Hospital.

This study maintained Patient data confidentiality in accordance with the ethical standers of the Helsinki 
declaration and the national committee for BioEthics (NCBE) at King Abdulaziz city for science and technology, Saudi Arabia.

\section{Funding}

This project was supported by the Taif University Research Support Project Number (TURSP-2020/37), Taif University, P.O. Box 11099, Taif, 21944, Saudi Arabia.

\section{Disclosure}

The authors report no conflicts of interest in this work.

\section{References}

1. Roth GA, Johnson C, Abajobir A, et al. Global, regional, and national burden of cardiovascular diseases for 10 causes, 1990 to 2015. $\mathrm{J} \mathrm{Am}$ Coll Cardiol. 2017;70(1):1-25. doi:10.1016/j.jacc.2017.04.052

2. Danzi S, Klein I. Thyroid disease and the cardiovascular system. Endocrinol Metab Clin North Am. 2014;43(2):517-528. doi:10.10 16/j.ecl.2014.02.005

3. Dillmann WH. Cellular action of thyroid hormone on the heart. Thyroid. 2002;12(6):447-452. doi:10.1089/105072502760143809

4. Danzi S, Klein I. Thyroid hormone and the cardiovascular system. Med Clin North Am. 2012;96(2):257-268. doi:10.1016/j.mcna.2012.01.006

5. Kahaly GJ, Dillmann WH. Thyroid hormone action in the heart. Endocr Rev. 2005;26(5):704-728. doi:10.1210/er.2003-0033

6. Biondi B, Palmieri EA, Lombardi G, Fazio S. Effects of thyroid hormone on cardiac function: the relative importance of heart rate, loading conditions, and myocardial contractility in the regulation of cardiac performance in human hyperthyroidism. J Clin Endocrinol Metab. 2002;87(3):968-974. doi:10.1210/jcem.87.3.8302

7. Canaris GJ, Manowitz NR, Mayor G, Ridgway EC. The colorado thyroid disease prevalence study. Arch Intern Med. 2000;160(4):526534. doi:10.1001/archinte.160.4.526

8. Klein I, Danzi S. Thyroid disease and the heart. Circulation. 2007;116 (15):1725-1735. doi:10.1161/CIRCULATIONAHA.106.678326

9. Klein I, Zipes DP, Libby P. Endocrine disorders and cardiovascular disease. In: Braunwald's Heart Disease: A Textbook of Cardiovascular Medicine. 7th ed; 2005:2051-2065.

10. Frost L, Vestergaard P, Mosekilde L. Hyperthyroidism and risk of atrial fibrillation or flutter: a population-based study. Arch Intern Med. 2004;164(15):1675-1678. doi:10.1001/archinte.164.15.1675

11. Ruggeri RM, Trimarchi F, Biondi B. L-Thyroxine replacement therapy in the frail elderly: a challenge in clinical practice. Eur $J$ Endocrinol. 2017;177(4):R199-R217. doi:10.1530/EJE-17-0321

12. Evangelopoulou ME, Alevizaki M, Toumanidis S, et al. Mitral valve prolapse in autoimmune thyroid disease: an index of systemic autoimmunity? Thyroid. 1999;9(10):973-977. doi:10.1089/thy.1999.9.973

13. Biondi B, Palmieri EA, Fazio S, et al. Endogenous subclinical hyperthyroidism affects quality of life and cardiac morphology and function in young and middle-aged patients*. J Clin Endocrinol Metab. 2000;85(12):4701-4705. doi:10.1210/jcem.85.12.7085

14. Sawin CT, Geller A, Wolf PA, et al. Low serum thyrotropin concentrations as a risk factor for atrial fibrillation in older persons. $N$ Engl J Med. 1994;331(19):1249-1252. doi:10.1056/NEJM199411103311901

15. Parle JV, Maisonneuve P, Sheppard MC, Boyle P, Franklyn JA. Prediction of all-cause and cardiovascular mortality in elderly people from one low serum thyrotropin result: a 10-year cohort study. Lancet. 2001;358(9285):861-865. doi:10.1016/S0140-6736(01)06067-6
16. Rothberger GD, Gadhvi S, Michelakis N, Kumar A, Calixte R, Shapiro LE. Usefulness of serum triiodothyronine (T3) to predict outcomes in patients hospitalized with acute heart failure. $\mathrm{Am} \mathrm{J}$ Cardiol. 2017;119(4):599-603. doi:10.1016/j.amjcard.2016.10.045

17. Duntas LH. Thyroid disease and lipids. Thyroid. 2002;12(4):287293. doi: $10.1089 / 10507250252949405$

18. Razvi S, Ingoe L, Keeka G, Oates C, McMillan C, Weaver JU. The beneficial effect of L-thyroxine on cardiovascular risk factors, endothelial function, and quality of life in subclinical hypothyroidism: randomized, crossover trial. J Clin Endocrinol Metab. 2007;92 (5):1715-1723. doi:10.1210/jc.2006-1869

19. Staub JJ, Althaus BU, Engler H, et al. Spectrum of subclinical and overt hypothyroidism: effect on thyrotropin, prolactin, and thyroid reserve, and metabolic impact on peripheral target tissues. Am J Med. 1992;92(6):631-642. doi:10.1016/0002-9343(92)90782-7

20. Hak AE, Pols HAP, Visser TJ, Drexhage HA, Hofman A, Witteman JCM. Subclinical hypothyroidism is an independent risk factor for atherosclerosis and myocardial infarction in elderly women: the Rotterdam study. Ann Intern Med. 2000;132(4):270-278. doi:10. 7326/0003-4819-132-4-200002150-00004

21. Su W, Zhao XQ, Wang M, Chen H, Li HW. Low T3 syndrome improves risk prediction of in-hospital cardiovascular death in patients with acute myocardial infarction. J Cardiol. 2018;72 (3):215-219. doi:10.1016/j.jjcc.2018.02.013

22. Chang C-Y, Chien Y-J, Lin P-C, Chen C-S, Wu M-Y. Nonthyroidal illness syndrome and hypothyroidism in ischemic heart disease population: a systematic review and meta-analysis. $J$ Clin Endocrinol Metab. 2020;105(8):8. doi:10.1210/clinem/dgaa310

23. Iervasi G, Molinaro S, Landi P, et al. Association between increased mortality and mild thyroid dysfunction in cardiac patients. Arch Intern Med. 2007;167(14):1526-1532. doi:10.1001/archinte.167.14.1526

24. Welsh KJ, Stolze BR, Yu X, Podsiadlo TR, Kim LS, Soldin SJ. Assessment of thyroid function in intensive care unit patients by liquid chromatography tandem mass spectrometry methods. Clin Biochem. 2017;50(6):318-322. doi:10.1016/j.clinbiochem.2016.11. 022

25. Doğan S, Dursun H, Can H, Ellıdokuz H, Kaya D. Long-term assessment of coronary care unit patient profile and outcomes: analyses of the 12-years patient records. Turkish J Med Sci. 2016;46 (3):801-806. doi:10.3906/sag-1502-88

26. Alventosa-Zaidin M, Guix Font L, Benitez Camps M, et al. Right bundle branch block: prevalence, incidence, and cardiovascular morbidity and mortality in the general population. Eur J Gen Pract. 2019;25(3):109-115. doi:10.1080/13814788.2019.1639667

27. Clark AL, Goode K, Cleland JGF. The prevalence and incidence of left bundle branch block in ambulant patients with chronic heart failure. Eur J Heart Fail. 2008;10(7):696-702. doi:10.1016/j. ejheart.2008.05.001

28. Al-Ghamdi MA. Morbidity pattern and outcome of patients admitted in a coronary care unit: a report from a secondary hospital in southern region, Saudi Arabia. J Community Hosp Intern Med Perspect. 2018;8(4):191-194. doi:10.1080/20009666.2018.1500421

29. Abdulaziz Qari F. Thyroid hormone profile in patients with acute coronary syndrome. Iran Red Crescent Med J. 2015;17:7. doi:10.5812/ircmj.26919v2

30. Kannan L, Shaw PA, Morley MP, et al. Thyroid dysfunction in heart failure and cardiovascular outcomes. Circ Heart Fail. 2018;11(12): e005266. doi:10.1161/CIRCHEARTFAILURE.118.005266

31. Loh KC, Eng PC. Prevalence and prognostic relevance of sick euthyroid syndrome in a medical intensive care unit.. Ann Acad Med Singapore. 1995;24(6):802-806.

32. Bouthoorn S, Valstar GB, Gohar A, et al. The prevalence of left ventricular diastolic dysfunction and heart failure with preserved ejection fraction in men and women with type 2 diabetes: a systematic review and meta-analysis. Diabetes Vasc Dis Res. 2018;15 (6):477-493. doi:10.1177/1479164118787415 
33. Akintoye E, Briasoulis A, Egbe A, et al. National trends in admission and in-hospital mortality of patients with heart failure in the United States (2001-2014). J Am Heart Assoc. 2017;6(12):12. doi:10.1161/ JAHA.117.006955

34. Ten Haaf ME, Bax M, Ten Berg JM, et al. Sex differences in characteristics and outcome in acute coronary syndrome patients in the Netherlands. Netherlands Hear J. 2019;27(5):263-271. doi:10.10 07/s12471-019-1271-0

35. Kindermann M. How to diagnose diastolic heart failure: a consensus statement on the diagnosis of heart failure with normal left ventricular ejection fraction by the Heart Failure and Echocardiography Associations of the European Society of Cardiology. Eur Heart J. 2007;28(21):2686. doi:10.1093/eurheartj/ehm 379
36. Owan TE, Hodge DO, Herges RM, Jacobsen SJ, Roger VL, Redfield MM. Trends in prevalence and outcome of heart failure with preserved ejection fraction. $N$ Engl J Med. 2017;177(4):251-259. doi:10.1530/EJE-17-0321

37. Hasdai D. Acute coronary syndromes in patients with pre-existing moderate to severe valvular disease of the heart: lessons from the Euro-Heart Survey of acute coronary syndromes. Eur Heart J. 2000;85(12):623-629. doi:10.1210/jcem.85.12.7085

38. Soeiro A, Araújo VA, Vella JP, et al. Is there any relationship between TSH levels and prognosis in acute coronary syndrome? Arq Bras Cardiol. 2000;132(4):113-118. doi:10.7326/0003-4819-132-4-200002150-00004

39. Åsvold BO, Bjøro T, Platou C, Vatten LJ. Thyroid function and the risk of coronary heart disease: 12-year follow-up of the HUNT Study in Norway. Clin Endocrinol (Oxf). 2020;105(8):911-917. doi:10.1210/clinem/ dgaa 310

\section{Publish your work in this journal}

The International Journal of General Medicine is an international, peer-reviewed open-access journal that focuses on general and internal medicine, pathogenesis, epidemiology, diagnosis, monitoring and treatment protocols. The journal is characterized by the rapid reporting of reviews, original research and clinical studies across all disease areas. The manuscript management system is completely online and includes a very quick and fair peer-review system, which is all easy to use. Visit http://www.dovepress.com/ testimonials.php to read real quotes from published authors. 